\title{
International System for Human Cytogenetic or Cytogenomic Nomenclature (ISCN): Some Thoughts
}

\author{
Thomas Liehr \\ Institute of Human Genetics, Jena University Hospital, Friedrich Schiller University, Jena, Germany
}

\section{Keywords \\ ISCN $\cdot$ Cytogenetics $\cdot$ Cytogenomics $\cdot$ Band level $\cdot$ Idiograms}

End of the year 2020, the new edition of ISCN was published [McGowan-Jordan et al., 2020]. As the content of this new edition has been already commented by others [Miller and Madan, 2021], here just 3 other points in connection with ISCN in general and the 2020 edition in particular are discussed.

First, there is the name change of the booklet being the "bible" of each cytogeneticist, which was already done from ISCN version 2013 to ISCN version 2016. ISCN was for decades the "International System for Human Cytogenetic Nomenclature." In ISCN version 2016 a major name change was done to "International System for Human $C y$ togenomic Nomenclature," and just commented with 9 words, as: it was done "to reflect the changes in technology under its purview." There was neither a detailed substantiation for this change, nor a definition what "cytogenomics" is; both have also not been added in the 2020 edition. According to the literature, the term "cytogenomics" showed up first in 1999 in a French paper [Bernheim, 1999] and was since then mainly used instead of saying "cytogenetics and genomics approaches" [Silva et al., 2019]; i.e., cytogenomics stands for technical applications in the field of cytogenetics and molecular genetics and genomics. Alternatively, it was suggested that the word cytogenomics could also indeed be standing for "cyto(post)genomics" [Iourov, 2019]. Yet, the term cy-

karger@karger.com

(c) 2021 S. Karger AG, Basel

www.karger.com/cgr

Karger" togenomics has been used in scientific literature in overall 22 years only about 400 times (https://pubmed.ncbi.nlm. nih.gov/), and while "cytogenetics" is included in Wikipedia, this is not the case for "cytogenomics."

Second, looking at ISCN editions 2009, 2013, 2016, and 2020 , the front page underwent major changes. Up to the 2009 edition one or more chromosomes were depicted on the front page. On the covers of ISCN 2013 and 2016 editions, chromosomes became first smaller and then more schematic, but were still present. The actual 2020 edition was published with a front page not showing chromosomes anymore. In exchange, there are 14 vertical lanes, each lane built by 26 differently colored horizontal bars. The 364 bars have 5 different colors (the same 5 colors as the publisher's logo comprises) and are vaguely reminiscent of sequencing results. Still, apart from nanopore technique, only either the 4 bases guanine, adenine, thymine, and cytosine or the 4 bases guanine, adenine, thymine, and methylated cytosine can be sequenced at a time. As there is no cover legend available this puzzle remains unresolved.

Finally, there is the following point: ISCN provides since its 1995 version "schematic representations of chromosomes corresponding to approximately $300,400,550,700$ and 850 bands" [McGowan-Jordan et al., 2020]. This sentence includes the word "approximately", which suggests, o.k., the band levels shown in the idiograms are not always exactly fitting the given band resolutions; however, deviations to expect are not more than \pm 5 , maybe. Also, as ISCN otherwise rules to follow exactly in nomenclature, one 
Table 1. Number of bands per chromosome at the so-called haploid band levels 300, 400, 550, 700, and 850

\begin{tabular}{|c|c|c|c|c|c|}
\hline \multirow[t]{2}{*}{ Chromosome } & \multicolumn{5}{|c|}{ Band level } \\
\hline & 300 & 400 & 550 & 700 & 850 \\
\hline 1 & 21 & 28 & 44 & 61 & 65 \\
\hline 2 & 20 & 30 & 40 & 50 & 63 \\
\hline 3 & 19 & 27 & 36 & 50 & 62 \\
\hline 4 & 14 & 26 & 32 & 45 & 47 \\
\hline 5 & 15 & 21 & 33 & 43 & 47 \\
\hline 6 & 16 & 23 & 33 & 44 & 50 \\
\hline 7 & 15 & 18 & 26 & 33 & 44 \\
\hline 8 & 14 & 18 & 28 & 40 & 40 \\
\hline 9 & 14 & 16 & 22 & 39 & 41 \\
\hline 10 & 14 & 14 & 28 & 34 & 42 \\
\hline 11 & 11 & 15 & 32 & 34 & 36 \\
\hline 12 & 13 & 15 & 25 & 39 & 41 \\
\hline 13 & 12 & 14 & 21 & 24 & 36 \\
\hline 14 & 12 & 14 & 18 & 24 & 32 \\
\hline 15 & 14 & 16 & 22 & 24 & 32 \\
\hline 16 & 11 & 13 & 15 & 21 & 25 \\
\hline 17 & 10 & 12 & 14 & 22 & 24 \\
\hline 18 & 9 & 11 & 14 & 16 & 20 \\
\hline 19 & 7 & 11 & 11 & 19 & 19 \\
\hline 20 & 8 & 10 & 10 & 18 & 20 \\
\hline 21 & 8 & 8 & 10 & 12 & 14 \\
\hline 22 & 8 & 8 & 12 & 16 & 16 \\
\hline $\mathrm{X}$ & 12 & 19 & 30 & 38 & 40 \\
\hline $\mathrm{Y}$ & 8 & 8 & 11 & 11 & 11 \\
\hline Overall & 305 & 395 & 567 & 757 & 867 \\
\hline Deviations & +5 & -5 & +17 & +57 & +17 \\
\hline
\end{tabular}

The determined real band numbers and the deviations from the given band numbers in ISCN 2020 [McGowan-Jordan et al., 2020] are listed.

could expect the exact band numbers are provided somewhere in the book - however, they are not. In Table 1, the counting done on the chromosomal bands shown in the idiograms of ISCN 2020, Figure 5, is documented. This resulted in: ISCN band levels 300 and 400 comprise indeed 305 and $395( \pm 5)$ bands, respectively. ISCN band levels 550 and 850 show deviations as 567 and $867(+17)$ bands, and the 700-band level is indeed a 757-band level (+57 bands). Maybe this could be adapted in the next edition.

Overall, the use of the word "cytogenomics" or a title page of ISCN avoiding chromosomes may be a try to address human geneticists being focused on sequencing rather than chromosomes or chromosomics [Claussen, 2005]; and this is a good and necessary goal. Especially, as cytogeneticists see more and more molecular genetic reports about gross copy number variants, being principally cytogenetically visible but evaluated using the nomen- clature originally meant for monogenic disorders and SNPs deriving from the "Standards and Guidelines for the Interpretation of Sequence Variants" as pathogenic/ likely pathogenic/likely benign/benign or variant of unknown significance [Richards et al., 2015].

In conclusion, as 124 of 151 text pages of ISCN deal with cytogenetics and molecular cytogenetics and only 27 pages ( $18 \%)$ of the book are about microarray, regionspecific assay and sequence-based nomenclature, a return to the name "International System for Human Cytogenetic Nomenclature" may be considered for the next edition, perhaps with the addition - "including nomenclature for microarrays, region-specific assays and sequencebased approaches."

\section{Conflict of Interest Statement}

The author has no conflicts of interest to declare.

\section{Funding Sources}

Not applicable.

\section{Author Contributions}

This paper has only one author, who is fully responsible for the paper's content.

References

Bernheim A. Exploration du génome dans les proliférations malignes: de la cytogénétique à la cytogénomique. Ann Pathol. 1999;19(5 Suppl):S1-3.

Claussen U. Chromosomics. Cytogenet Genome Res. 2005;111(2):101-6.

Iourov IY. Cytopostgenomics: What is it and how does it work? Curr Genomics. 2019;20:77-8.

McGowan-Jordan J, Hastings RJ, Moore S, editors. ISCN 2020: An International System for Human Cytogenomic Nomenclature. Basel: Karger; 2020.

Miller K, Madan K. ISCN 2020 compared to ISCN 2016. ECA-Newsletter. 2021;47:2-11.

Richards S, Aziz N, Bale S, Bick D, Das S, GastierFoster J, et al. Standards and guidelines for the interpretation of sequence variants: A joint consensus recommendation of the American College of Medical Genetics and Genomics and the Association for Molecular Pathology. Genet Med. 2015;17:405-24.

Silva M, de Leeuw N, Mann K, Schuring-Blom H, Morgan S, Giardino D, et al. European guidelines for constitutional cytogenomic analysis. Eur J Hum Genet. 2019;27:1-16. 